
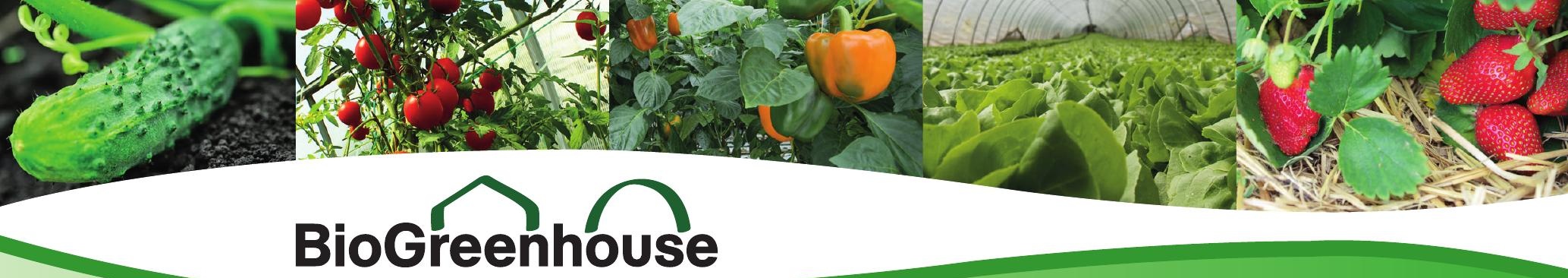

Food safety

\title{
Potential food hazards from organic greenhouse horticulture
}

To meet the Global Challenges for Humanity, sustainable and environmentally sound approaches to crop production are critical tools. Organic production systems are characterised by the wise use of crop input resources. Despite the lack of supporting medical evidence (Smith-Spangler et al., 2012) or evidence of acute pesticide concentrations in non-organic conventional produce (EFSA, 2014), organically produced plant foods are often assumed to be safer and to have stronger health promoting properties than produce produced in conventional or integrated production systems. However, the narrow boundary between animal and organic crop husbandry, coupled with the increasing use of recycled materials as a source of plant nutrients and the application of permitted plant protection products to organic crops pose risks to human health. Awareness of these hazards is low. This factsheet describes the critical hazards in organic greenhouse horticulture (OGH) crop production and identifies the crucial knowledge gaps.

\section{Problems and reasons for research}

According to the Codex Alimentarius (2014), a food safety hazard is defined as a "biological, chemical or physical agent in, or condition of food with the potential to cause an adverse health effect". Biological hazards are related to virus, bacteria, fungi and protozoa, which in the context of fruits and vegetables mostly arise from the fecal-oral route of transmission. Chemical hazards may occur in the form of heavy metals, undesired organic contaminants; in particular persistent organic products, the presence of mycotoxins as well as antimicrobial compounds. Whereas physical hazards are related to foreign bodies (soil, stones, bone chips, metal and glass items) that could cause injury. The safety of plant foods, especially with respect to biological and chemical hazards, needs to be managed during primary



Figure 1. Potential biological hazard through animal droppings and bloody excretions in soil grown spinach. production as these hazards may not necessarily be counteracted following crop harvest or during processing. Furthermore, despite the EU-common regulation for organic production, national standards may be more variable in their restrictions. This jungle of national standards poses a hazard per se (regulatory hazard).

\section{The specific situation in organic greenhouse horticulture}

The environmental conditions within organic greenhouse horticulture (glasshouses or polytunnels) are different from organic field production with respect to the critical environmental factors such as the light spectrum, light intensity; temperature and amplitude of temperature changes and relative humidity. These factors influence microbial colonisation of plants. In addition, differences can also occur with respect to the technology used I: i) advanced technology heated/cooled (HT) greenhouses with crops grown in soil amended with organic materials, ii) advanced technology heated/cooled organic greenhouses using growing media (derived from composted waste materials), and iii) medium (MT) and low (LT) technology greenhouses using soil with added animal wastes. Crops under protection are shielded from wild or domestic animals. Nevertheless, animals and their excreta may occur in $\mathrm{OGH}$ as an integral part of crop nutrient management, exposing organic crops to zoonotic organisms. The links between the specific conditions prevailing in OHG and food safety concerns have only been studied to a limited extent scientifically and need more immediate attention. 

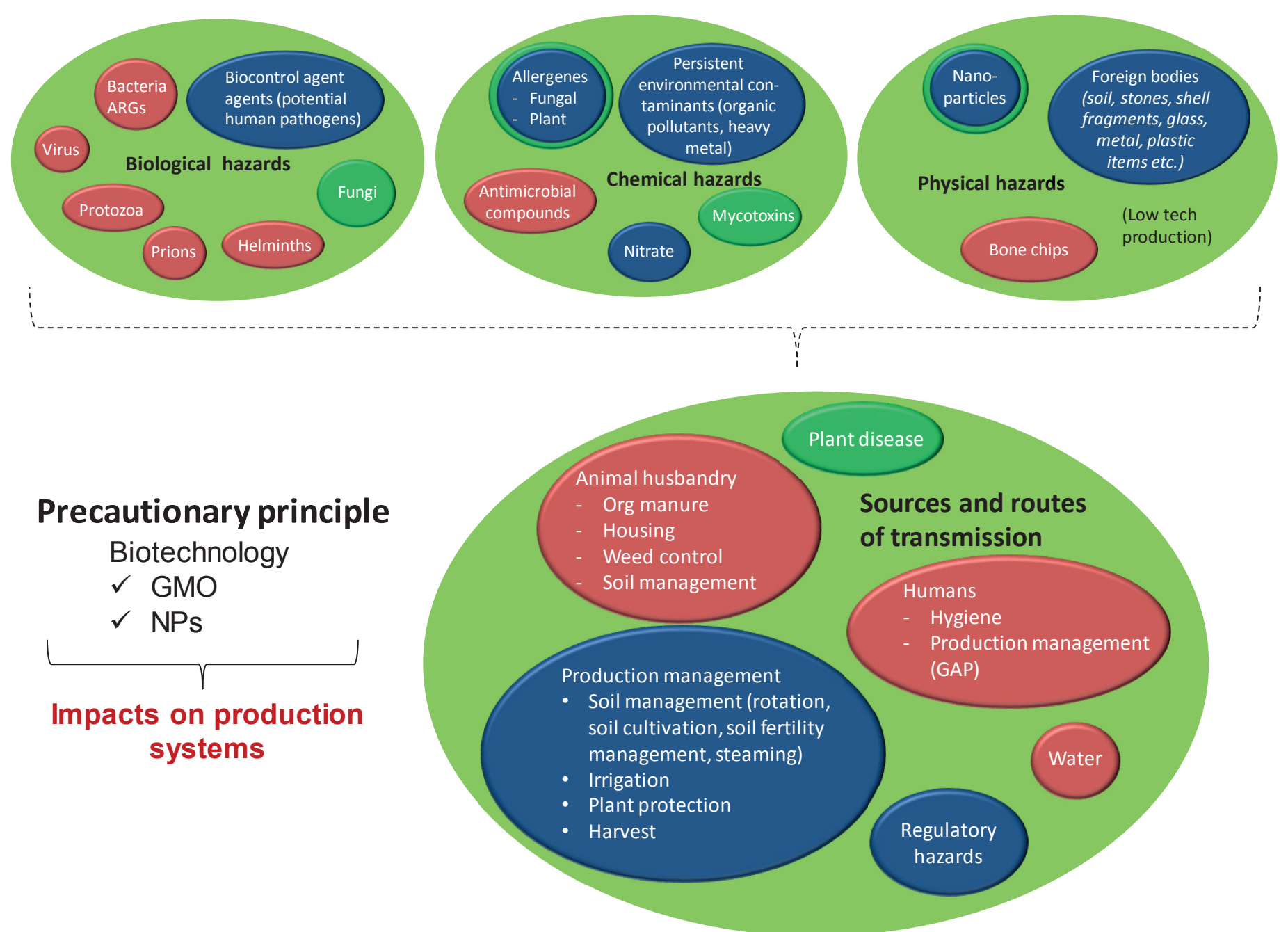

Figure 2. Food safety interactions in primary production (ARGs: Antibiotic Resistance Genes; GAP: Good Agricultural Practice).

\section{Biological hazards}

In plant production; water, organic manures, soil, livestock and wild animals, humans as well as cross contamination during harvesting and post-harvest handling have been identified as principal vehicles for transmission of enteric human pathogens. The various biological hazards differ in infectious dose, incubation time as well as manifestation and severity of illness. Few outbreaks have been explicitly linked to organically produced commodities (e.g. 1995: verocytotoxigenic Citrobacter freundii associated with organically grown parsley; 2011: Escherichia coli 0104:H4 associated with fenugreek seed, Germany/France, number of registered cases: 3842, of these 855 with HUS, 53 deaths; 2012: E. coli 0157:H7 associated with spinach and spring seeds, USA, number of registered cases: 33). The low number of food safety cases linked to organic production systems and especially OGH is rather a consequence of the limited production area, in contrast to the scale of conventional production, coupled with the general problem of positively linking food illnesses to fresh produce contamination. In particular, fruits and vegetables are highly perishable and quickly move through the supply chain.

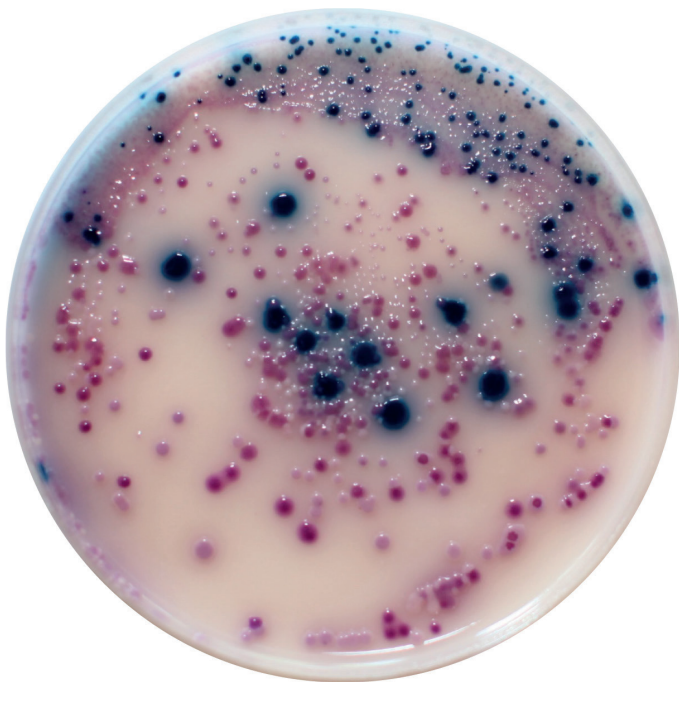

Figure 3. Microbial colonies extracted from organically grown lettuce grown on chromogenic agar (blue colonies: presumptive $E$. coli; mangenta colonies: presumptive Salmonella spp.). 
survival of contaminants when transmitted by organic manure or irrigation water. Thorough risk assessment for biological hazards in OGH in terms of probability and impact on human health is lacking. Biological activity has been claimed to reduce biological food hazards, but scientific evidence has not been established yet.

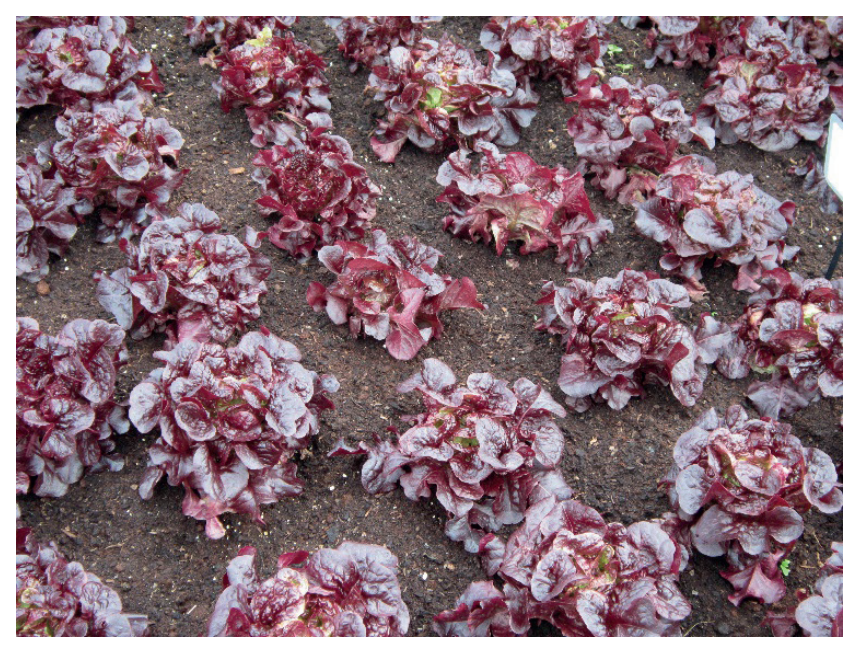

Figure 4. Organic salad leaf production.

\section{Chemical hazards}

Protected cropping systems with reduced temperature changes provide optimised conditions for nitrogen mineralization. This is important for leafy vegetable production, which is dependent on high nitrogen availability up to harvest. Considerably higher nitrate and nitrite content has been found in organically grown leaf vegetables as opposed to inflorescence and fruit vegetables. This may also be attributed to restricted light transmittance and light intensity through the cladding material on a greenhouse structure. Nitrate threshold values vary for different crops and harvesting times according to EU regulations (Commission regulation (EC) No $1881 / 2006)$.

Although the use of synthetic chemical compounds is prohibited in EU Organic legislation and/or guidelines for organic production, heavy metals, persistent organic chemical pollutants as well as residual pesticides and pharmaceutical and personal care products may be introduced into the cropping system unintentionally through various waste materials. While, higher cadmium and lead concentrations were observed in some organically grown field crops than that recorded in conventional produce no data is available for crops produce in $\mathrm{OGH}$.

In addition, to control fungal foliar diseases (in particular late blight of potato and tomato), the use of copper (copper hydroxide, copper oxychloride, copper sulfate, copper oxide, copper octanoate) as foliar sprays are permitted under EU-regulations, however they may be, prohibited in some EU-member states due to environmental and health concerns.
Among mycotoxins the most relevant in $\mathrm{OGH}$ include alternariatoxins produced by species of Alternaria, patulin produced by Penicillium spp. and other fungi, fumonisins mainly produced by Fusarium proliferatum, and aflatoxins and ochratoxins produced by Aspergillus spp.

\section{Strategic research lines}

Recommended topics for further investigation are:

- Hygiene awareness and food safety strategies in primary organic greenhouse production.

- Interactions between crop physiological properties and food safety in $\mathrm{OGH}$, esp. survival of existing and emerging human pathogens.

- Impact of biological activity on prevalence, survival and proliferation of human pathogens in OHG.

- Risk assessment for human pathogens under diverse scenarios in $\mathrm{OGH}$.

- Hazard Analysis Critical control Points for OGH.

- Reduced use of copper to control foliar diseases through environmental control measures

- Occurrence of mycotoxins in organically grown greenhouse products.

References: Dorais, M., Alsanius, B.W. 2015. Advances and trends in organic fruit and vegetable production systems. Hort. Rev. 43: 185-268. EFSA, 2014. The 2011 European Union report on pesticide residues in food. EFSA Journal 12: 3864. FAO/WHO, 2014. Codex Alimentarius: principles and guidelines for the conduct of microbiological risk assessment, in: Codex Alimentarius (Ed.), CAC/GL 30-1999. FAO/WHO, Rome, pp. 1-5. Smith-Spangler, C., Brandeau, M.L., Hunter, G.E., Bavinger, J.C., Pearson, M., Eschbach, P.J., Sundaram, V., Liu, H., Schirmer, P., Stave, C., Olkin, I., Dravata, D.M., 2012. Are organic foods safer or healthier than conventional alternatives? A systematic review. Annals of Internal Medicine 157(5):348-66.

Acknowledgement: This work was supported by COST Action FA1105 "Towards a sustainable and productive EU organic greenhouse horticulture".

\section{DOI: http://dx.doi.org/ 10.18174/375668}

